\title{
Simulasi Dinamika Molekuler Kuantum dari Densitas Muatan Plasma untuk Sistem Sederhana
}

\author{
Albert Zicko Johannes* \\ Program Studi Fisika, Fakultas Sains dan Teknik, Universitas Nusa Cendana, \\ Jl.Adi Sucipto-Penfui, Kota Kupang, Nusa Tenggara Timur, Indonesia \\ *Penulis PenanggungjawabE-mail : : zickojohannes@staf.undana.ac.id
}

\begin{abstract}
ABSTRAK
Pemodelan ab-initio Dinamika Molekuler Kuantum dari densitas muantan plasma telah telah dilakukan. Metode yang digunakan adalah Dinamika Molekuler CarParrinello, dimana metode ini dapat mensimulasikan pergerakan dinamis dari elektron dan ion pada suatu temperatur rata-rata. Penelitian ini bertujuan mensimulasikan perubahan densitas muatan dari kluster atom Hidrogen dan atom Oksigen (10 atom) pada temperatur $1300 \mathrm{~K}$. Hasil menunjukkan densitas muatan setelah perubahan waktu 0.120 ps untuk setiap kluster mengalami perubahan bandwidth distribusi densitas. Untuk kluster $\mathrm{H}$ sebesar $0.021 \mathrm{bohr}^{-3}$, kluster H-O $(50 \% \mathrm{H}-50 \% \mathrm{O})$ sebesar $0.069 \mathrm{bohr}^{-3}$ dan kluster O sebesar $-0.241 \mathrm{bohr}^{-3}$.
\end{abstract} Perubahan ini menunjukkan sebaran densitas dipengaruhi oleh jenis ion plasma.

Kata Kunci : Dinamika Molekuler Kuantum; Plasma; Densitas muatan; Dinamika Molekul Car-Parrinello.

\begin{abstract}
The ab-initio Quantum Molecular Dynamics modeling of plasma charge density is performed. The Method used in this research is Car-Parrinello Molecular Dynamics, which is can simulate the dynamics of electrons and ions at some average temperature. This research purpose is to simulate the change in charge density of Hidrogen and Oxygen atom cluster (10 atoms) at the average temperature $1300 \mathrm{~K}$. The results show the charge density after time difference 0.120 ps for each clusters experience change in bandwidth. For $\mathrm{H}$ cluster is $0.021 \mathrm{bohr}^{-3}, \mathrm{H}-\mathrm{O}$ cluster $(50 \% \mathrm{H}-$ $50 \% \mathrm{O}$ ) is $0.069 \mathrm{bohr}^{-3}$ and $\mathrm{O}$ cluster is $-0.241 \mathrm{bohr}^{-3}$. This change shows that the density distribution is influenced by the types of plasma ions.

Keywords : Quantum Molecular Dynamics; Plasma, Charge Density; Car- Parrinello Molecular Dynamics
\end{abstract}




\section{Pendahuluan}

Plasma dalam ilmu fisika adalah keadaan fase materi keempat setelah padat, cair, dan gas. Urutan ini didasarkan oleh energi dari partikelpartikel penyusun materi. Semakin tinggi energi yang dimiliki setiap partikel dalam materi maka semakin tinggi kecepatan dan temperaturnya. Plasma merupakan materi dalam keadaan gas yang terionisasi oleh energi tinggi sehingga ion dan elektron terbentuk di dalamnya. Beberapa contoh materi plasma ini adalah matahari, bintang, petir, ionosfer, api, lampu neon, layar plasma serta plasma fusi nuklir.

Plasma sudah sering diteliti karena cakupannya yang luas diberbagai bidang [1,2,3]. Dalam mempelajari plasma ada parameter yang sering menjadi acuan yaitu densitas dan temperatur. Densitas dari plasma berkisar dari $10^{14} \mathrm{partikel/cc}$ sampai dengan dibawah densitas dari materi padat yaitu $10^{23}$ partikel/cc. Untuk temperatur berkisar $0.1 \sim 100 \mathrm{eV}$ $\left(10^{3} \sim 10^{6} \mathrm{~K}\right)$ [3]. Secara teoritis kedua nilai ini berada pada daerah materi padat hangat atau warm dense matter (WMD). "Hangat" berarti temperatur dalam kisaran $10^{3} \sim 10^{6} \mathrm{~K}$. "Padat" berarti densitas diantara $10^{21} \sim 10^{25}$ partikel/cc.
Pada daerah WMD plasma dapat ditempati oleh atom, molekul, elektron, ion atau gabungan dari dua atau lebih ion (dimmer, trimmer, dll). Semua isi dari plasma ini bergerak secara dinamis dan dapat berinteraksi satu sama lain. Oleh karena itu dalam mempelajari plasma cocok menggunakan pemodelan simulasi dinamika molekuler.

Simulasi dinamika molekuler plasma secara umum sangat kompleks dan melibatkan banyak partikel [1,2,3], pada penelitian ini hal tersebut disederhanakan dengan mensimulasikan sistem yang jenis dan jumlah partikel lebih sedikit. Lebih lanjut pemodelan simulasi pada penelitian ini bertujuan untuk melihat perubahan densitas muatan (elektron) dari plasma khusus pada temperatur $1300 \mathrm{~K}$.

\section{Metode Perhitungan}

\subsection{Simulasi Dinamika Molekuler}

\section{Car- Parrinello}

Dinamika Molekuler CarParrinello (DM-CP) adalah suatu metode untuk mensimulasikan pergerakan elektron dan ion pada suatu temperatur rata-rata. Metode ini menggunakan perhitungan energi total ab-initio dari Teori Fungsional Rapat Elektron (Density functional Theory) atau DFT [4]. Metode ini 
Metode ini menggunakan perhitungan energi total ab-initio dari Teori Fungsional Rapat Elektron (Density functional Theory) atau DFT [4]. Metode ini mempersingkat waktu komputasi. Oleh karena itu metode DM-CP banyak dipakai untuk simulasi dinamika molekuler.

Metode DM-CP menggunakan dua jenis massa dengan dinamika masingmasing. Yaitu massa ion dan massa fiktif elektron. Derajat kebebasan elektron dimisalkan sebagai suatu massa fiktif , sehingga elektron bergerak dengan dinamika tersendiri. Sehingga orbital elektron dan posisi ion divariasikan secara bersama-sama untuk mencapai kesetimbangan atau energi minimum. Lagrangian dari sistem berguna untuk mencari energi minimum dan simulasi dinamika molekuler.

Dalam perhitungan energi minimum digunakan DFT yaitu persamaan orbital elektron Kohn-Sham yang bentuknya mirip persamaan Schrödinger sebagai berikut :

$$
-\frac{\hbar^{2}}{2 m} \nabla^{2} \psi_{i}(r)+V(r) \psi_{i}(r)=\varepsilon_{i} \psi_{i}(r)
$$

Bagian pertama dari persamaan (1) adalah bagian energi kinetik, bagian kedua adalah energi potensial total $V(r)$ dan bagian ketiga $\varepsilon_{i}$ adalah energi total sistem orbital elektron. Di dalam DFT energi potensial total terdiri dari tiga bagian yaitu :

$$
V(r)=V_{\text {inti }}(r)+\phi(r)+f_{x c}^{t}(n(r)
$$

Setelah energi elektron minimum dilanjutkan ke penggunaan persamaan gerak dinamika molekuler dimana untuk ion adalah :

$$
M \ddot{R}_{l}=-\frac{\partial V\left[R_{l}, \psi_{k}\right]}{\partial R_{l}}+\sum_{k m} \Lambda_{k m} \psi_{m}
$$

dan untuk elektron fiktif adalah :

$$
\mu \psi_{k}=-\frac{\partial V\left[R_{l}, \psi_{k}\right]}{\partial \psi_{k}}+\sum_{m} \Lambda_{k m} \psi_{m}
$$

dimana $\quad M=$ massa ion, $R_{l}=$ posisi ion, $\mu=$ massa fiktif elektron, $\psi_{k}$ $=$ orbital elektron $\mathrm{ke}-\mathrm{k}, \quad \Lambda_{\mathrm{km}}=$ matriks parameter pengali lagrange.

Pembahasan lebih rinci tentang metode ini dapat dilihat pada tulisan Dipojono, H.K. [4].

\subsection{Langkah perhitungan}

Plasma yang disimulasikan pada perhitungan ini dibatasi untuk plasma atom hidrogen dan oksigen yang tercipta pada temperatur $1300 \mathrm{~K}$. Langkah pertama pada simulasi ini adalah memodelkan sistem atom. Sistem yang digunakan penelitian ini 
adalah suatu sistem sederhana yang terdiri dari kluster atom pada kotak persegi berukuran $1000 \AA^{-3}$ dengan syarat batas periodik, dimana dengan syarat batas ini atom yang melewati dinding akan muncul kembali disisi lain kotak atau dengan kata lain densitas sistem akan tetap terjaga (konstan).

Pada perhitungan digunakan 2 jenis atom berbeda yakni atom Hidrogen $(\mathrm{H})$ dan atom Oksigen $(\mathrm{O})$ dan berjumlah total 10 atom. Sistem 10 atom ini divariasikan densitasnya antara $0,01 \mathrm{~g} /$ cc dan 0,26 g/cc. Dimana 0,01 g/cc untuk sistem dengan 10 atom berupa $\mathrm{H}$ dan $0,26 \mathrm{~g} / \mathrm{cc}$ untuk 10 atom berupa $\mathrm{O}$, sedangkan untuk pembanding digunakan sistem $50 \%$ atom $\mathrm{H}$ dan $\mathrm{O}$ dengan densitas sebesar $0,14 \mathrm{~g} / \mathrm{cc}$. Konversi densitas ini dalam bentuk densitas elektron dan ion ditunjukkan untuk setiap simulasi dapat dilihat pada tabel. Selain itu penggunaan sistem ini bertujuan menghemat waktu simulasi dan mendekati sistem plasma asli yang kompleks dengan suatu sistem sederhana. Setelah dilakukan pemodelan sistem atom, langkah berikutnya dalam simulasi ini adalah meminimalkan energi dari elektron ke keadaan energi dasar dengan DFT. Kemudian dilanjutkkan dengan perhitungan dengan metode DM-CP. Semua perhitungan diatas akan menggunakan software open-source Quantum Esspresso atau $Q E$ yaitu cp.x [5]. Sedangkan untuk menampilkan hasil perhitungan digunakan Xcrysden [6].

\subsection{Input $\mathrm{QE}$}

Perhitungan dengan software $Q E$ diperlukan beberapa input utama yakni jenis dan posisi atom, bentuk dan ukuran kisi serta jenis potensial semu. Pada perhitungan ini ditentukan jenis atom adalah $\mathrm{H}$ dan $\mathrm{O}$, serta bentuk kisi adalah kubik dengan panjang kisi 10 Á. Potensial semu yang digunakan adalah GGA Becke-Lee-Yang-Parr (BLYP).

Selain itu perhitungan DM-CP memerlukan penentuan nilai massa semu, pada perhitungan digunakan massa semu sebesar 700 satuan masa atom (atomic mass unit) atau amu. Tidak lupa dimasukkan nilai temperatur $1300 \mathrm{~K}$.

Tabel 1. Tabel densitas plasma dari elektron dan ion

\begin{tabular}{lllll}
\hline No & Jenis Atom & $\begin{array}{l}\text { Jumlah tiap } \\
\text { Atom }\end{array}$ & $\begin{array}{l}\text { Densitas elektron } \\
\left(\mathrm{cc}^{-3}\right)\end{array}$ & $\begin{array}{l}\text { Densitas Ion }\left(\mathrm{cc}^{-}\right. \\
\mathbf{3}^{-}\end{array}$ \\
\hline 1 & $\mathrm{H}$ & $\mathrm{H}-10$ & $1,00 \times 10^{22}$ & $1,00 \times 10^{22}$ \\
2 & $\mathrm{O}$ & $\mathrm{O}-10$ & $8,00 \times 10^{22}$ & $1,00 \times 10^{22}$ \\
3 & $\mathrm{H}$ dan O & $\mathrm{H}-5, \mathrm{O}-5$ & $4,50 \times 10^{22}$ & $1,00 \times 10^{22}$ \\
\hline
\end{tabular}




\section{Hasil dan Pembahasan}

Hasil simulasi DM-CP dapat dilihat pada gambar 1 dan 2. Gambar 1 dan 2 menunjukkan hasil simulasi pada keadaan awal (waktu $\mathrm{t}=0 \mathrm{ps}$ ), keadaan menengah $(\mathrm{t}=0,048 \mathrm{ps})$, dan keadaan $\operatorname{akhir}(\mathrm{t}=0,120 \mathrm{ps})$.

Gambar 1 menunjukkan isosurface 3 dimensi dari densitas muatan. Nilai isosurface ini diambil pada nilai 0.01 bohr $^{-3}$ atau 0,005 $\AA^{-3}$ Isosurface ini mengindikasikan lapisan densitas elektron pada suatu permukaan bernilai sama. Terlihat digambar pada keadaan awal semua kluster terlihat tidak jauh berbeda, hal ini dikarenakan posisi awal ion adalah sama yang berbeda hanya jenis atomnya. Terlihat distribusi densitas elektron ion $\mathrm{H}$ lebih kecil dari densitas atom $\mathrm{O}$, hal ini sesuai dengan teori dimana atom $\mathrm{O}$ mengandung lebih banyak elektron daripada atom $H$. Selanjutnya pada keadaan menengah terlihat hal yang mirip disemua kluster yaitu sebaran densitas elektron berkumpul ditengah ruang. Sedangkan pada keadaan akhir posisi ion-ion untuk kluster atom $\mathrm{H}$ tersebar ke seluruh ruang, sehingga sebaran densitas elektron menyebar ke sudut-sudut ruang membuat bagian tengah ruang menjadi kosong. Hal berbeda untuk kluster atom $\mathrm{H}-\mathrm{O}$ serta kluster atom $\mathrm{O}$, posisi akhir ion-ion masih berkumpul ditengah ruang dan membentuk daerah sebaran densitas elektron yang cukup besar dibagian tengah. Pada kedua kluster ini ion-ion cenderung terlihat lebih terikat dan sulit menyebar. Hal menarik lainnya terlihat pada kluster atom $\mathrm{H}$, ion $\mathrm{H}$ terlihat menyebar secara berpasangan. Terbentuk ikatan dimer antara ion $\mathrm{H}$ satu dengan lainnya.

Selanjutnya gambar 2 menunjukkan pola kontur isoline 2 dimensi. Perubahan isoline dibagi menjadi 5 daerah pewarnaan dengan urutan warna pelangi dan dalam skala logaritmik, dimana warna merah menunjukkan nilai densitas terkecil (mendekati nol) dan sebaliknya warna ungu nilai densitas terbesar (lebih besar atau sama dengan 0,5806 bohr $^{-3}$ ), Pola kontur ini diambil pada bidang permukaan YZ, ZX dan XY, pada tiga lapisan yaitu lapisan atas, tengah dan bawah serta pada tiga waktu yang berbeda awal, menengah dan akhir. Hasil kontur ini memperjelas analisis pada gambar 1, terlihat pada keadaan awal, menengah dan akhir (kecuali untuk kluster atom $\mathrm{H}$ pada keadaan akhir) pola kontur warna biru-ungu sebagai daerah dengan nilai densitas besar terlihat lebih banyak terkumpul pada lapisan tengah. Sedangkan untuk kluster atom $\mathrm{H}$ pada keadaan akhir pola kontur biru-ungu tersebar disetiap lapisan. 


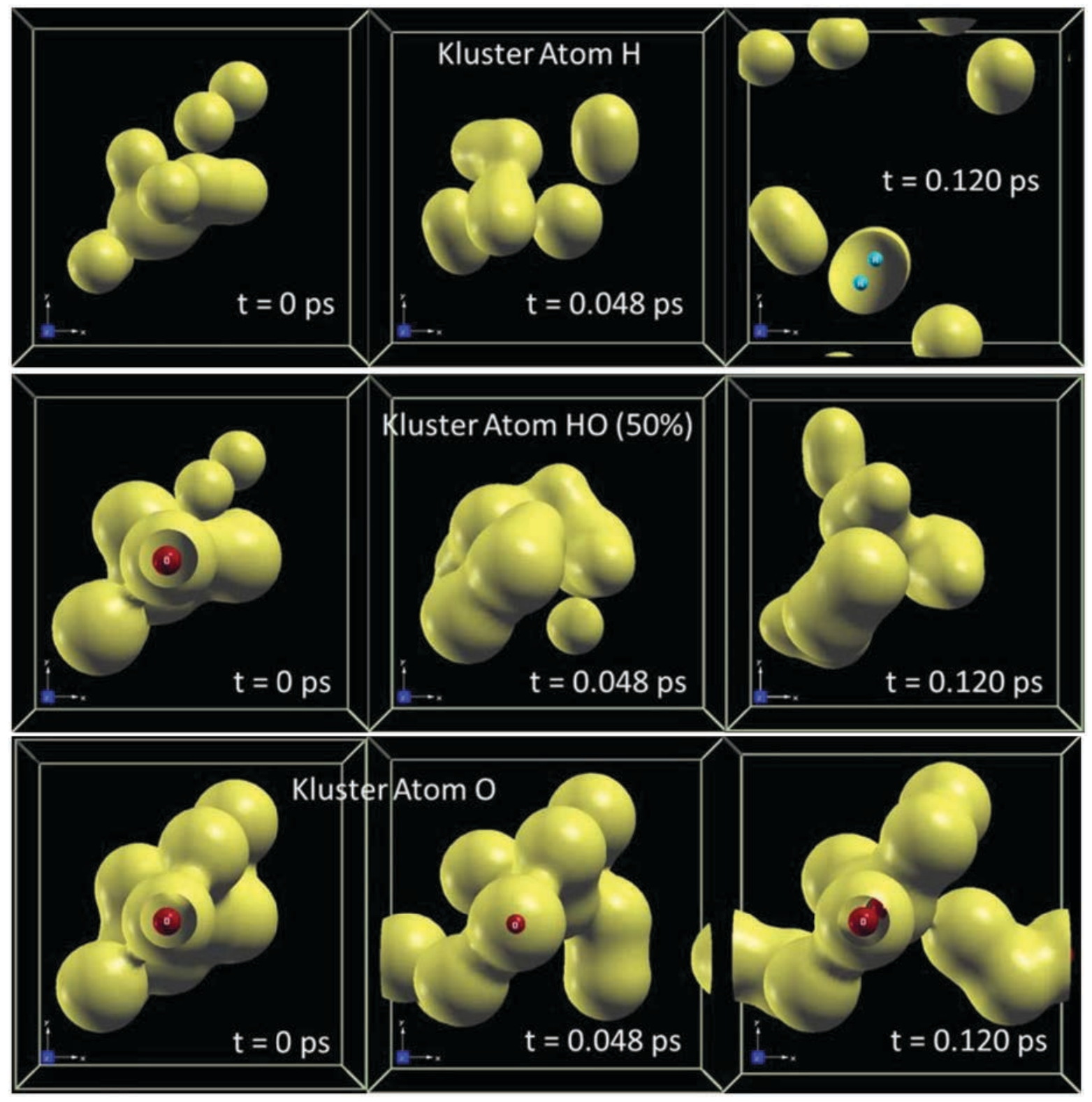

Gambar 1. Isosurface 3-dimensi densitas muatan elektron pada ion untuk permukaan 0,01 bohr $^{-3}$, pada tiga keadaan waktu simulasi berbeda awal $\mathrm{t}=0 \mathrm{ps}$, menengah $\mathrm{t}=0,048 \mathrm{ps}$, dan akhir $\mathrm{t}=0,120 \mathrm{ps}$.

Dari hasil perhitungan diperoleh juga perubahan lebar pita (bandwidth) sebaran densitas muatan elektron dari keadaan awal ke keadaan berikutnya. Hasil ini dapat dilihat pada gambar 3. Terlihat untuk $\mathrm{H}$ dan $\mathrm{H}-\mathrm{O}$ bertambah lebar sedangkan untuk $\mathrm{O}$ berkurang.
Selisih perubahan dari keadaan awal ke keadaan akhir $\mathrm{H}$ sebesar 0,021 bohr ${ }^{-3}$, HO sebesar 0,069 bohr $^{-3}$ dan untuk O sebesar -0,241 bohr ${ }^{-3}$. Nilai ini menunjukkan sebaran densitas elektron sangat dipengaruhi jenis ion atom plasmanya. 


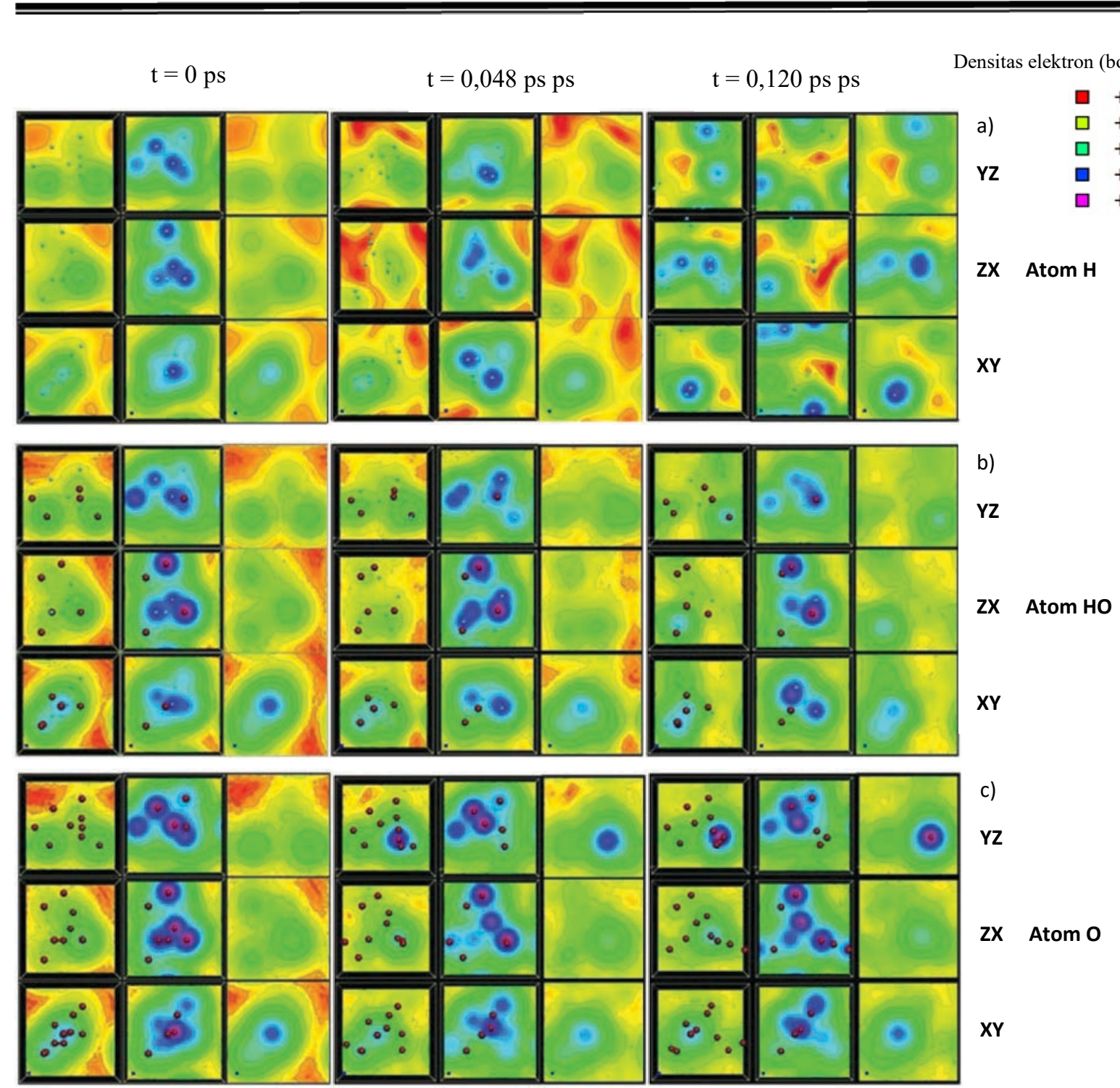

Gambar 2. Isolines 2-dimensi densitas elektron $\left(\mathrm{bohr}^{-3}\right)$ pada ion untuk permukaan, untuk tiga bidang YZ, $\mathrm{ZX}$, dan $\mathrm{XY}$, dengan tiga lapisan berbeda bawah, tengah dan atas dari kiri ke kanan berturut-turut, serta tiga keadaan waktu simulasi berbeda awal $\mathrm{t}=0 \mathrm{ps}$, menengah $\mathrm{t}=0,048 \mathrm{ps}$, dan akhir $\mathrm{t}=0,120 \mathrm{ps}$. Kluster atom $\mathrm{H}$ (a), Kluster gabungan atom $\mathrm{H}-\mathrm{O}$ dengan campuran $50 \%$ (b). Kluster atom $\mathrm{O}$ (c).

Elektron dalam pergerakannya berusaha mencari suatu nilai setimbang atau nilai energi minimum dari posisi awalnya, pada kluster $\mathrm{H}$ dan $\mathrm{H}-\mathrm{O}$ elektron cenderung bergerak menyebar untuk setimbang (nilai bandwidth sebaran densitas elektron bertambah lebar) sedangkan untuk kluster $\mathrm{O}$ elektron lebih cenderung bergerak mengumpul (nilai bandwidth sebaran densitas elektron bertambah kecil).

\section{Simpulan}

Perubahan densitas muatan elektron pada sistem dapat disimulasikan dengan baik menggunakan metode DM-CP. Pergerakan ion serta perubahan sebaran densitas muatan elektron pada temperatur $1300 \mathrm{~K}$ dapat terlihat jelas pada sistem sederhana ini. Dari hasil isosurfaces dan isolines elektron, kluster $\mathrm{H}$ bergerak lebih bebas sedangkan 


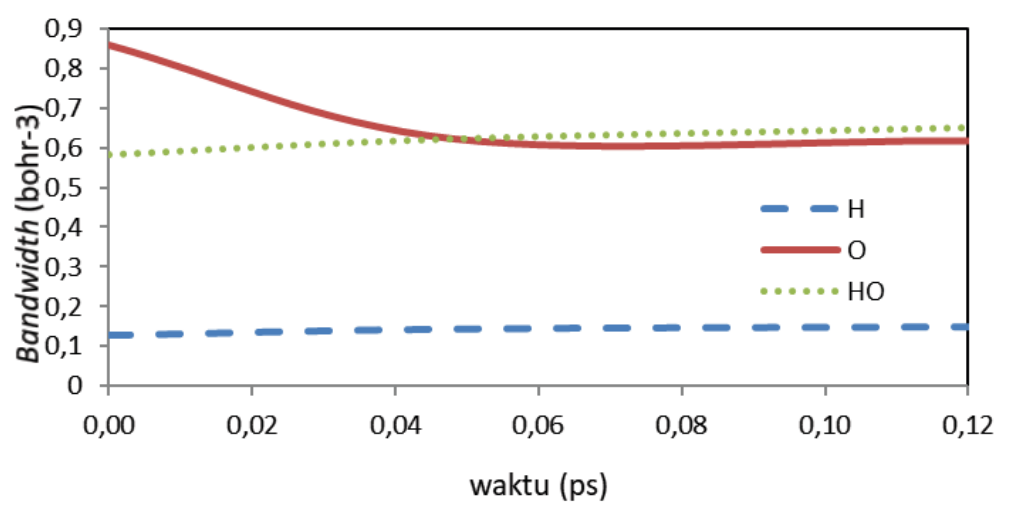

Gambar 3. Bandwidth sebaran densitas elektron $\left(\right.$ bohr $\left.^{-3}\right)$ dari keadaan awal ke keadaan berikutnya.

elektron pada kluster $\mathrm{H}-\mathrm{O}$ dan $\mathrm{O}$ cenderung lebih sulit bergerak dan terikat, terlihat pada keadaan akhir kedua kluster tersebut yang terkumpul di tengah ruang. Berikutnya dari nilai bandwidth sebaran densitas elektron, kluster $\mathrm{H}$ dan $\mathrm{H}-\mathrm{O}$ elektron cenderung bergerak menyebar untuk setimbang (nilai bertambah besar) sedangkan untuk kluster $\mathrm{O}$ elektron lebih cenderung bergerak megumpul (nilai semakin kecil). Jenis ion plasma mempengaruhi gerak elektron serta penyebarannya.

\section{Referensi}

1. Miloshevsky, G., \& Hassanein, A. (2014). Quantum Modeling of Electronic Charge Density in Warm Dense Matter. IEEE Transactions on Plasma Science, 42(10), 2508-2509.

2. Collins, L., Kwon, I., Kress, J., Troullier, N. and Lynch, D. (1995) Quantum Molecular Dynamics
Quantum Molecular Dynamics Simulations of Hot, Dense Hydrogen. Physical Review E, 52: 6202-6219.

3. Kahane, S. (2017) Quantum Molecular Dynamics Simulations of Warm Dense Li Plasma. Open Journal of Modelling and Simulation , 5: 189217.

4. Dipojono, H.K.(2001) Simulasi Dinamika Mokekul (Sebuah Pengantar), di dalam Prosiding Seminar Nasional Hamburan Neutron dan Sinar-X ke 4: 11-12, Serpong, ISSN 1410-7686

5. Giannozzi, P., Andreussi, O., Brumme, T., Bunau, O., Nardelli, M. B., Calandra, M., ... \& Colonna, N. (2017). Advanced capabilities for materials modelling with Quantum ESPRESSO. Journal of Physics: Condensed Matter, 29(46), 465901.

6. Kokalj, A. , XCrySDen - a New Program for Displaying Crystalline Structures and Electron Densities (1999) J. Mol. Graphics Modelling, 17:171-179. 